\title{
Clarification of the reaction at the solution interface of pyrite during oil agglomeration for developing desulfurization and coal cleaning efficiency
}

\author{
Q. Wang ${ }^{1}$, H. Niida ${ }^{1}$, P. Apar ${ }^{1}$, Q. Chen ${ }^{1}$, L. Gui ${ }^{1}$, Q. Qian ${ }^{1}$, \\ N. Mitsumura ${ }^{1}$, T. Endou ${ }^{1}$, S. Animesh ${ }^{1}$, H. Kurokawa ${ }^{1}$, \\ K. Sekiguchi ${ }^{1} \&$ K. Sugiyama ${ }^{2}$ \\ ${ }^{I}$ Department of Environmental Science and Technology, \\ Graduate School of Science and Engineering Saitama University, Japan \\ ${ }^{2}$ Hachinohe National College of Technology, Japan
}

\begin{abstract}
Recently, large amounts of waste fine coals have been produced which are difficult to treat because of the high ash content and inorganic sulfuric compounds. In order to make efficient use of waste fine coal, the retrieval technique is necessary for recovery of coal combustible content from fine waste coals. Nowadays a floatation process is able to operate, but it is impractical for developing countries due to high costs. An oil agglomeration process can deal with these problems. In this study, we investigate the mechanism of the solution interface reaction on oil agglomeration in order to separate pyrite sulfur effectively from waste fine coal. For this purpose, we adjusted the $\mathrm{pH}$ of the solution of oil agglomeration experiments to the basic condition, which changed the surface characteristics to hydrophilicity from hydrophobicity. Furthermore, $\mathrm{pH}$ and dissolved oxygen changes of the solution were continually monitored and free ferric ions of the waste liquid were measured by flame atomic absorption spectrometry. These factors have a relationship with the oxidation and surface reaction of pyrite sulfur in the solution. Under high basic conditions, pyrite sulfur reduction indicated high values since the pyrite surface became hydrophilic due to covering of the surface of the pyrite sulfur by ferric hydroxide. As a result, the pyrite content did not recover together with hydrophobic carbonaceous content especially under high basic conditions.
\end{abstract}


However, coal cleaning efficiency, especially of combustible matter recovery, dropped under these conditions due to increased ion intensity.

Keywords: oil agglomeration process, coal cleaning, waste fine coal, pyrite sulfur, hydrophobicity, hydrophilicity, $\mathrm{pH}$, dissolved oxygen, ash content, desulfurization, free ferric iron ion.

\section{Introduction}

Nowadays, coal production increases continuously due to the increase in mechanization in coal mining and demand in its related fields of application worldwide. In particular, coal consumption in China has a multiplying trend, but the problem of waste fine coals is serious because the coal cleaning efficiency is poor. The coals which have high ash content and inorganic sulfurs are difficult to get available as resources and cause spontaneous combustion leading in turn to air pollution, land occupation, soil pollution and water contamination $[1,2]$. In order to make efficient use of waste fine coals, a retrieval technique is necessary for recovery of combustible content of coals from waste fine coals. A floatation process can treat these, but the cost is the major problem in the operation in developing countries. Therefore, the oil agglomeration process has attracted attention as a method of dealing with these problems, which is a coal cleaning technique used for differences of surface characteristics between carbonaceous and ash content [3]. The hydrophobic oil which is an aggregation agent selectively attaches hydrophobic carbonaceous content and forms the agglomerate. From the difference in particle size between aggregate and ash content (Figure 1), we can recover only the carbonaceous content and remove the ash content $[4,5]$. From our previous experiments of different particle sizes, we succeeded in recovering only coal combustible carbonaceous content from waste coals [6]. In recent days influencing factors of the oil agglomeration process were investigated by experiments using different grade coal and it was concluded that aromatic and aliphatic functional groups of carbonaceous content had an important function. However, the oil agglomeration process has not been put to practical use because the coal cleaning efficiency is low and usage of recovered carbonaceous content is not discussed $[7,8]$. We need to accumulate the data for commercial viability of oil agglomeration in the future.

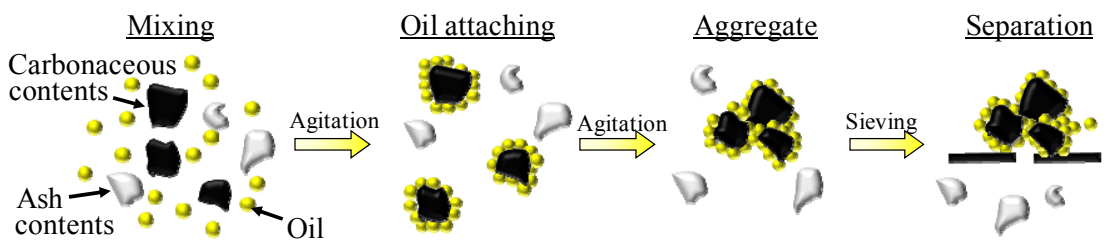

Figure 1: $\quad$ Principle and concept of oil agglomeration for coal cleaning.

Pyrite sulfur is a mineral and sulfuric material in coal and needs to be rejected by coal cleaning, and also the oil agglomeration process [9]. However, this is 
difficult because surfaces of pyrite tend to indicate hydrophobicity, whereas the sulfate sulfur which is also contained in coal as a sulfuric mineral showing hydrophilicity. Pyrite sulfur easily oxidizes in water with dissolved oxygen (DO) according to the following reactions $[10,11]$.

$$
\begin{gathered}
2 \mathrm{FeS}_{2}+7 \mathrm{O}_{2}+2 \mathrm{H}_{2} \mathrm{O} \rightarrow 2 \mathrm{Fe}^{2+}+4 \mathrm{SO}_{4}{ }^{2-}+4 \mathrm{H}^{+} \\
\mathrm{Fe}^{2+}+1 / 2 \mathrm{O}_{2}+2 \mathrm{H}^{+} \rightarrow 2 \mathrm{Fe}^{3+}+\mathrm{H}_{2} \mathrm{O} \\
\mathrm{FeS}_{2}+2 \mathrm{Fe}^{3+} \rightarrow 2 \mathrm{~S}+3 \mathrm{Fe}^{2+}
\end{gathered}
$$

Reaction (1) and reaction (2) arise from $\mathrm{pH} 4$ to $\mathrm{pH} 9$ and the solution becomes acidic due to releasing of a proton. Then these steps shift reaction (3) and elemental sulfur are produced on the surface of pyrite sulfur, which is why pyrite sulfur represents hydrophobicity. Moreover, hydrophobic pyrites are recovered with hydrophobic carbonaceous content and the reduction ratio of sulfur may decrease. Above $\mathrm{pH}$ 9, hydrophilic ferric hydroxides cover the surface of pyrite at reaction (4).

$$
2 \mathrm{FeS}_{2}+15 / 2 \mathrm{O}_{2}+7 \mathrm{H}_{2} \mathrm{O} \rightarrow 2 \mathrm{Fe}(\mathrm{OH})_{3}+4 \mathrm{SO}_{4}{ }^{2-}+8 \mathrm{H}^{+}
$$

Although it can be possible to reject pyrite sulfur due to hydrophilicity, protons are also released and this reaction shifts (1) or (2) soon. There are several problems of disposing and removing pyrite sulfur as mentioned above and methods are required to treat it $[9,11]$.

In this study, we used an oil agglomeration process in order to recover the carbonaceous content from waste fine coal which was difficult to treat by established coal cleaning processes. In addition, we set out to make efficient use of coal resources of exhaustible energy. Then the mechanism of the solution interface reaction of pyrite sulfur on oil agglomeration under basic solutions was researched because it led to effective separation of pyrite sulfur. The reasons why the oxidation reaction occurred during the oil agglomeration process for a massive amount of pyrite sulfur in the waste fine coal are complicated and are not clear in detail, so $\mathrm{pH}$, dissolved oxygen (DO) and free ferric iron ion were measured. In the basic solution, we proved oil agglomeration and found coal clean efficiency and sulfur reduction for each $\mathrm{pH}$.

\section{Experimental procedures}

\subsection{Sample preparation}

In this study, the samples of waste fine coals were selected and collected from Chongqing Nantong coal mine in south-eastern China. Before our experiments, the fine coal samples were prepared below $75 \mu \mathrm{m}$ by sieving. The proximate of the coal samples was measured according to the Japanese industrial standard (JIS) method of JIS-M8812. The ultimate analyses of the samples were determined with a CHN corder (Model MT-6, Yanako Co. Ltd., Japan) and by 
the Eschka method of JIS-M8813 for total sulfur content. The results of proximate analysis and ultimate analysis of waste fine coal samples are shown in Table 1.

Table 1: $\quad$ Results of proximate and ultimate analysis of coal samples.

\begin{tabular}{|c|c|c|c|c|c|c|c|c|}
\hline \multicolumn{4}{|c|}{ Proximate analysis (wt.\%) } & \multicolumn{5}{|c|}{ Ultimate analysis (wt.\%) } \\
\hline Ash & $\mathrm{M}$ & VM & FC & $\mathrm{H}$ & $\mathrm{C}$ & $\mathrm{N}$ & $\mathrm{O}$ & $\mathrm{S}$ \\
\hline 54.1 & 4.1 & 23.8 & 18.0 & 2.2 & 20.2 & 0.32 & 11.3 & 9.6 \\
\hline
\end{tabular}

M: moisture, VM: volatile matter, FC: fixed carbon

\subsection{Determination of sulfur content in waste fine coals}

For the distribution of sulfur content in more detail, we measured organic sulfur, sulfate sulfur and pyrite sulfur in coal samples according to JIS-M8817 (Table 2). Although pyrite sulfur content of clean coal is usually below 1 wt.\%, that of these coal samples is much higher.

Table 2: $\quad$ Results of forms of sulfur in waste fine coals.

\begin{tabular}{ccc}
\hline $\begin{array}{c}\text { Organic sulfur } \\
\text { (wt.\%) }\end{array}$ & $\begin{array}{c}\text { Sulfate sulfur } \\
\text { (wt.\%) }\end{array}$ & $\begin{array}{c}\text { Pyrite sulfur } \\
\text { (wt.\%) }\end{array}$ \\
\hline 1.62 & 2.75 & 5.23 \\
\hline
\end{tabular}

\subsection{Experiments of oil agglomeration adjusted $\mathrm{pH}$ of solution}

The schematic diagram of the oil agglomeration procedure is shown in Figure 2, and the experimental conditions are given in Table 3. Firstly, we calibrated the $\mathrm{pH}$ of tap water with $\mathrm{NaOH}$ solution from $\mathrm{pH} 7$ to $\mathrm{pH} 14$ for its availability and solubility. If not solving, it interfere with agglomeration of the coal. Initial DO was $8.8 \mathrm{mg} / \mathrm{L}$. Secondly, coal samples were poured into a $500 \mathrm{~mL}$ beaker with four buffers and mixed. After the mixture became a suspension, vegetable oil as an aggregating agent was poured into the beaker and the aggregate was formed. When it was steady, the agglomerates in the water were filtered with a $75 \mu \mathrm{m}$ sieve. The resultant agglomeration products were separated from mineral matter (ash) content in waste fine coals below $75 \mu \mathrm{m}$. The agglomerates were filtered and dried overnight at room temperature, washed with ethanol and diethyl ether to remove oils in agglomeration, and then dried overnight at room temperature again $[6,7]$. Actually, for industrial applications, the solvent washing steps of agglomerates would not be necessary and coal/oil agglomerates could be used directly as fuel because of fewer pollutants in the oils. For the evaluation of experiments, we measured the weight and ash content of agglomerate using equations (5)-(10). Recovery $(R)$ is yield ratio but analysis of the component is needed. Then we worked out the sulfate sulfur reduction $(S S R)$ and pyrite sulfur reduction $(P S R)$ for the sulfur rejection. The efficiencies of coal cleaning were 
calculated by the percentages (wt.\%) of combustible matter recovery $(C M R)$, ash reduction $(A R)$ and efficiency index $(E I)$ from ash content in cleaned coal $[3,5]$. In the formula, agglom and feed denotes recovered agglomeration and coal samples, respectively, and $w t$ gives the weight unit (g). In equations (6)-(10), SS and $P S$ are the contents of sulfate sulfur and pyrite sulphur, respectively, and $C M$ is $100-$ (ash content) [8, 9].

$$
\begin{gathered}
R(\%)=100 \times w t_{\text {agglom }}(\mathrm{g}) / w t_{\text {feed }}(\mathrm{g}) \\
\operatorname{SSR}(\%)=100 \times\left(1-S S_{\text {agglom }}(\%) \times w t_{\text {agglom }}(\mathrm{g})\right) /\left(S S_{\text {feed }}(\%) \times w t_{\text {feed }}(\mathrm{g})\right. \\
P S R(\%)=100 \times\left(1-P S_{\text {agglom }}(\%) \times w t_{\text {agglom }}(\mathrm{g})\right) /\left(P S_{\text {feed }}(\%) \times w t_{\text {feed }}(\mathrm{g})\right. \\
C M R(\%)=100 \times C M_{\text {agglom }}(\mathrm{wt} . \%) \times w t_{\text {agglom }}(\mathrm{g}) /\left(C M_{\text {feed }}(\mathrm{wt} . \%) \times w t_{\text {feed }}(\mathrm{g})\right) \\
A R(\%)=100-100 \times A s h_{\text {agglom }}(\mathrm{wt} \%) \times w t_{\text {agglom }}(\mathrm{g}) /\left(A s h_{\text {feed }}(\mathrm{wt} . \%) \times w t_{\text {feed }}(\mathrm{g})\right) \\
E I(\%)=C M R(\%)+A R(\%)
\end{gathered}
$$

Table 3: Experimental conditions of oil agglomeration.

\begin{tabular}{c|c}
\hline Item & ExperimentalCondition \\
\hline Sample & Waste fine coal $: 15.0 \mathrm{~g}$ \\
Water & $200 \mathrm{~mL}$ \\
Oil & $5.00 \mathrm{~g}$ \\
Agitation 1 & Time $: 3 \mathrm{~min}$ Speed $: 1,500 \mathrm{rpm}$ \\
Agitation 2 & Time $: 3 \mathrm{~min}$ Speed $: 1,500 \mathrm{rpm}$ \\
Standingtime & $3 \mathrm{~min}$ \\
\hline
\end{tabular}

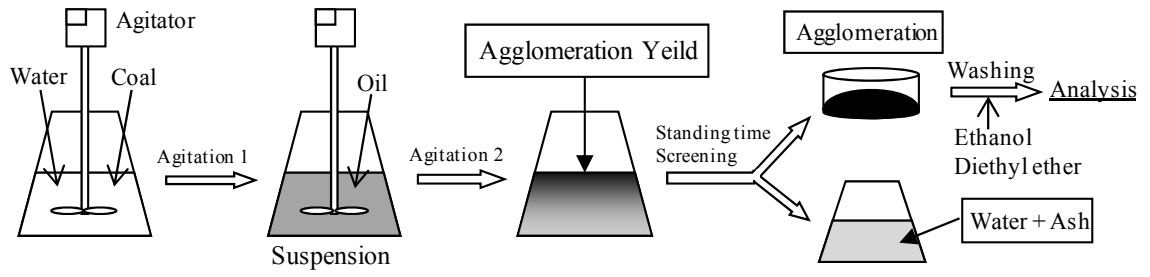

Figure 2: $\quad$ Schematic diagram for steps of oil agglomeration experiments.

\section{4 $\mathrm{pH}$ and DO variation of the adjusted basic solution during oil agglomeration experiments}

We continually measured $\mathrm{pH}$ and $\mathrm{DO}$ during oil agglomeration experiments under the same conditions in order to find out the mechanism of pyrite sulfur oxidation. Oxidation of pyrite sulfur occurs using DO and proton is released, which leads to the acidification of the solution. At high acidity $(<\mathrm{pH} 4)$, the surface of pyrite sulfur covers the elemental sulfur and this is said to be a reason for decrease of the desulfurization. In this study, we adjusted the $\mathrm{pH}$ to basic, but it is not known how much acidification occurs, the final descent of $\mathrm{pH}$ and the state of expenditure of DO in the solution. 


\subsection{Quantitative estimation of free ferric iron ion from pyrite sulfur oxidation}

We determined the quantity of iron ion by flame atomic absorption spectrometry and showed the experimental conditions detailed in Table 4. When pyrite sulfur oxidizes, ferric irons were released into the solution. However, in the high basic solution, this does not occur because of the formation ferric hydroxide around the surface of the pyrite sulfur particle. Then we measured the free ferric iron ion to make sure production of the ferric hydroxide occurred [12].

Table 4: Conditions for determining free ferric iron ion by flame atomic absorption spectrometry.

\begin{tabular}{l|c}
\hline \multicolumn{1}{c|}{ Item } & Condition \\
\hline Lamp (-) & D2-lamp \\
Wave number (nm) & 248.3 \\
Lamp current (mA) & 12 \\
Slit width (nm) & 0.2 \\
Frame type (-) & Air- $\mathrm{C}_{2} \mathrm{H}_{2}$ \\
Volume of acethylene (L/min) & 2.2 \\
Burner hight (mm) & 7 \\
\hline
\end{tabular}

At first, we picked the waste solution after oil agglomeration experiments and caused a portion of the ferric hydroxide to lyse completely by nitric acid fluid. Ferric iron became colloid and it needed to do so. Secondly the treated solution was diluted 100 times with ultrapure water. At last, we determined the iron ion by AA-7000 (SHIMAZU, Japan).

\section{Results and discussions}

\subsection{Clarification of the oxidation of pyrite sulfur during oil agglomeration}

\subsubsection{Influence of the variation of $\mathrm{pH}$ on the oxidation of pyrite sulfur}

From the results of Figure 3, pH variation stopped at around 8 only where we initially adjusted the solution to high basic, where it had $\mathrm{pH} 13$. On the other hands, most experiments were conducted under $\mathrm{pH} 4$ in spite of alteration to basic. These variations can be explained by the pyrite oxidation according to reaction formulae from (1) to (4). At basic, ferric hydroxides started to cover the surface of pyrite sulfur according to formula (4) and $\mathrm{pH}$ decreased. However, only under high basic conditions is the surface completely covered by the hydroxide and the reaction sites are occupied, which is why the decreasing $\mathrm{pH}$ of the solution slumbered around neutrality at an experiment of initial $\mathrm{pH} 13$. In turn, we think that the $\mathrm{pH}$ of most of the experiments became below 4 after the surfaces were covered by hydroxides with possible formation of elemental sulfur $[9,11]$. 


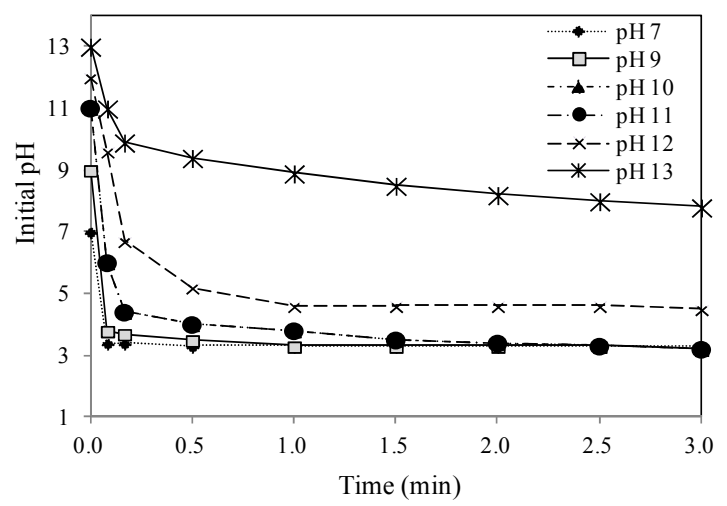

Figure 3: $\mathrm{pH}$ variations during oil agglomeration experiments against adjusted initial basic solution.

\subsubsection{Influence of the variation of $\mathrm{pH}$ on oxidation of pyrite sulfur under basic conditions}

The cause of stop of the decrease in $\mathrm{pH}$ may be the absence of DO by the expenditure based on the oxidation of pyrite sulphur, but the DO meter showed $8.8 \mathrm{mg} / \mathrm{L}$. Then we conducted an oil agglomeration experiment with an anoxia solution at $0.22 \mathrm{mg} / \mathrm{L}$ by treating the nitrogen which was bubbling initially. Consequently DO returned to $8.8 \mathrm{mg} / \mathrm{L}$ and we thought that DO was constantly provided by the agitation. Then there was no case that the oxidation reactions of pyrite sulfur stopped by the absence of DO.

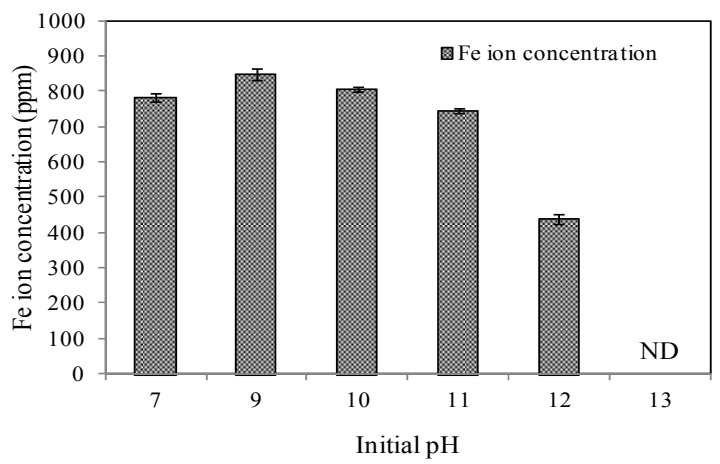

Figure 4: Determination of the quantity of iron ion in solution after oil agglomeration experiments by flame atomic absorption spectrometry.

\subsubsection{Elution amount of free ferric iron ion from oxidation of pyrite sulfur}

We researched the iron ion produced by chemical reactions (2) and (3) and quantitative estimation of ferric ion from Figure 4. Under high basic conditions, no iron ion was found, thus the above mentioned reactions in which ferric 
hydroxides cover the surface of pyrite sulfur as reaction (4) are dominant at initial $\mathrm{pH}$ values of $13[11,12]$. We also concluded that the decrease and stop of the $\mathrm{pH}$ value contributed to overlaying of the surface by hydroxides and the absence of reaction sites.

From these experiments, we did not confirm the form of the ferric iron, such as ion or colloid. We think that the ferric iron has extremely low solubility at ordinary $\mathrm{pH}$ values $(\mathrm{pH} \mathrm{7-10)}$ and the colloid of iron may been formed in the solution [14], where there was concern that precise determination of the quantity was not possible due to filtration of waste solution between water and solid. However, from Figure 3, oxidation reaction rate was much fast and hydroxide only formed at very high $\mathrm{pH}$ because final $\mathrm{pH}$ was around the ordinary $\mathrm{pH}$.

\subsection{Evaluation of oil agglomeration experiments adjusted to basic solution}

\subsubsection{Process yield and substantive value}

With increase of $\mathrm{pH}$ value, you can see a decrease of the $R$ value from Figure 5 and at most $R$ dropped at the rate of $20 \%$ from neutral to high basic. However, this does not show the constituents of the recovered agglomerate and we need to research in more detail.

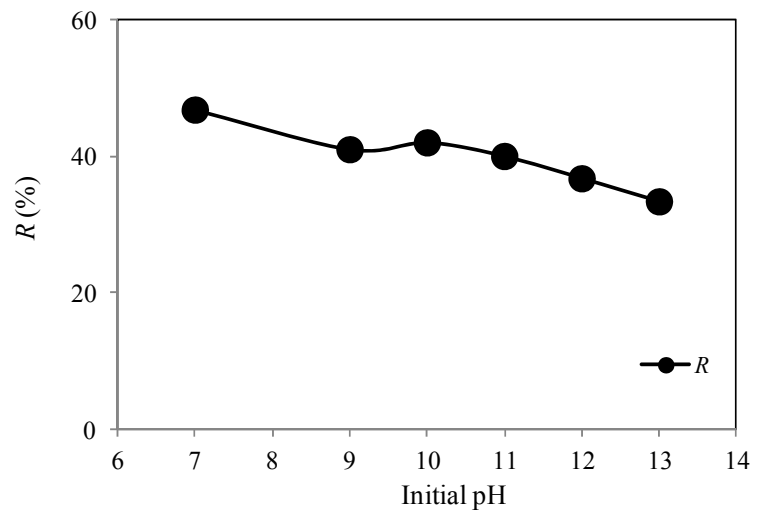

Figure 5: Quantitative recovery from waste fine coals by the oil agglomeration experiments against initial $\mathrm{pH}$.

\subsubsection{Reduction ratio of inorganic sulfur mineral under basic conditions}

We explained the rejection of two major inorganic thionic materials in coal shown in Figure 6. Hydrophilic sulfate sulfur was removed at all $\mathrm{pH}$ ranges but reduction of pyrite sulfur increased with a rise of $\mathrm{pH}$ value, especially under high basic conditions. This is thought to be because of the formation of hydroxide and the progressive hydrophilicity of pyrite sulfur [9]. On the other hand, reduction was low under low basic conditions because of insufficient production of hydroxides and possible generation of elemental sulfur. Besides, PSR at initial $\mathrm{pH} 12$ was comparatively elevated due to a small quantity of free ferric iron ion as shown in Figure 4. However, we did not check the formation of elemental 
sulfur. Measurement of the oxidation reduction potential or drawing of a Pourbaix diagram of iron will help us to understand the mechanism of oxidation of pyrite for the future $[14,15]$.

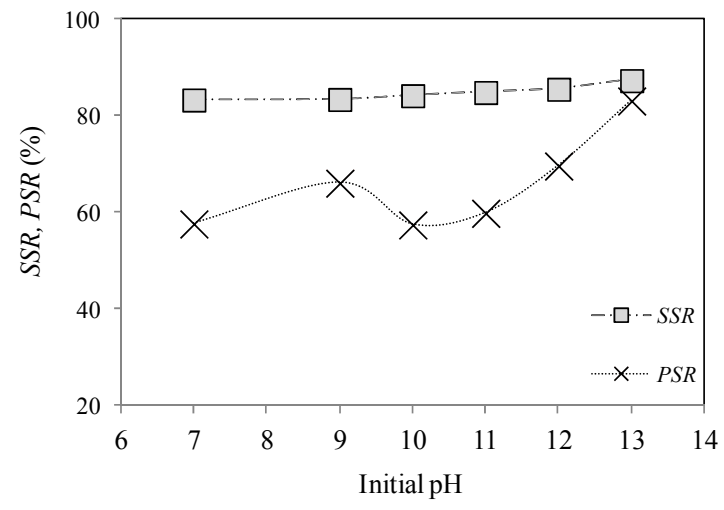

Figure 6: Removal of sulfate sulfur and pyrite sulfur by oil agglomeration based on adjusting $\mathrm{pH}$ of the solution.

\subsubsection{Coal cleaning efficiency affected by $\mathrm{pH}$ and oxidation of pyrite sulfur}

Each index was shown in Figure 7 against basic $\mathrm{pH}$ value. The association of all $A R$ were not seen but $C M R$ decreased with increase of $\mathrm{pH}$, and the behavior of $R$ was the same. It is thought that the drop is caused by a rise in ionic strength. Sodium ions in sodium hydroxide solution as a modifier usually have an electric charge neutralization action $[16,17]$. In the case of a small quantity, the negative charge of the coal surface is buffered and the zeta potential nears $0[18,19]$. However, when absolutely needed quantities increase, the potential is separated from 0, which leads to a fall of the agglomeration effect. Thus $C M R$ decreased under high basic conditions and $E I$ also decreased because of this.

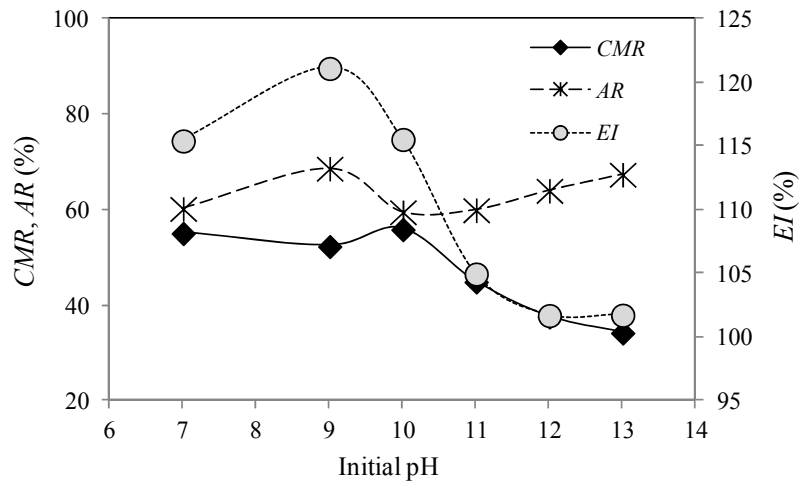

Figure 7: Coal cleaning efficiencies against initial $\mathrm{pH}$ of oil agglomeration experiments. 


\section{Conclusions}

In this study, we investigated the effect on oil agglomeration by adjusting basic $\mathrm{pH}$ solution in order to reject the pyrite sulfur from waste fine coal. Moreover, the mechanism of the solution interface reaction of oil agglomeration was clear in order to separate pyrite sulfur effectively. Under high basic conditions, pyrite sulfur reduction indicated high values since the pyrite surface became hydrophilic due to covering of the surface of pyrite sulfur by ferric hydroxide. As a result, the pyrite content was recovered together with the hydrophobic carbonaceous content especially under high basic conditions. So, coal cleaning efficiency, for example combustible matter recovery, decreased under these conditions because of increasing ion intensity. In the future, we will take on developing $C M R$ and $E I$ in order to gain high rejection of pyrite sulfur and coal cleaning efficiency to recovery more exhaustible resources from waste fine coal.

\section{Acknowledgement}

Some works of this study were supported by the special funds for Basic Research (B) (No. 22404022, FY2010 2012) of a Grant-in-Aid for Scientific Research of the Japanese Ministry of Education, Culture, Sports, Science and Technology (MEXT), Japan.

\section{References}

[1] World Energy Outlook 2007 - China's Energy Prospects, ISBN: 978-9264-02730-5, IEA.

[2] J. Gpiorek, Waste pyritic coal as a raw material for energetic industry, Fuel Processing Technology, 52, 175-182, 1997.

[3] A.F. Valdes, and B. Garcia, On the utilization of waste vegetable oils (WVO) as agglomerants to recover coal from coal fines cleaning waste (CFCW), Fuel, 85, 607-614, 2006.

[4] M.I. Alonso, A.F. Valdes, R.M. Martinez-Tarazona, and B. Garcia, Coal recovery from coal fines cleaning wastes by agglomeration with vegetable oils: effects of oil type and concentration, Fuel, 78, 753-759, 1999.

[5] A. Gurses, K. Doymus, and S. Bayrakceken, Selective oil agglomeration of brown coal: a systematic investigation of the design and process variables in the conditioning step, Fuel, 75, 1175-1 180, 1996.

[6] Q. Wang, N. Kashiwagi, P. Apaer, Q. Chen, Y. Wang, and T. Maezono, Study on coal recovery technology from waste fine Chinese coals by a vegetable oil agglomeration process, The Sustainable World, Ecology and the Environment, 142, 331-342, 2010.

[7] Q. Wang, N. Kashiwagi, P. Apaer, Q. Chen, Y. Wang, T. Maezono, and D. Niida, Recovery of combustible matter from waste fine Chinese coals by a waste vegetable oil agglomerating process and its combustion characteristics, Energy and Sustainability, Ecology and the Environment, 143, 327-338, 2011. 
[8] Q. Wang, H. Niida, P. Apaer, Q. Chen, L. Gui, Q. Qian, N. Mistumura, H. Kurokawa, K. Sekiguchi and K. Sugiyama, Influential factors on oil agglomeration process for coal recovery from different grade coal, Waste Management and the Environment VI, Ecology and The Environment, 163, 187-199, 2012.

[9] Y. Cebeci, U. Ulusoy and S. Simsek, Investigation of the effect of agglomeration time, ph and various salts on the cleaning of Zonguldak bituminous coal by oil agglomeration, Fuel, 81, 289-297, 2002.

[10] M. Misra, K. Bukka and S. Chen, The effect of growth medium of Thiobacillus Ferooxidans on pyrite flotation, Mineral Engineering, 9, 157168, 1996.

[11] P. B. Gissinger, M. Alnot, J. J. Ehrhardt and P. Behra Environ, Surface oxidation of pyrite as a function of pH, Sci Technol., 32, 2839-2845, 1998.

[12] F. Fujiwara, R. J. Rebagliati, J. Marrero, D. Gómez and P. Smichowski, Antimony as a traffic-related element in size-fractionated road dust samples collected in Buenos Aires, Microchemical Journal, 97, 62-67, 2011.

[13] J. Krysyna, and C.J. Barend, Relating coal oxidation and hydrophobicity: a petrographic approach, Fuel, 75, 1611-1616, 1996.

[14] M. Descostes, P. Vitorge and C. Beaucaire, Pyrite dissolution in media, Geochimica et Cosmochimica Acta, 68, 4559-4569, 2004.

[15] C. L. Celderia, V. S. T. Ciminelli, A. Dias and K. Osseo-Asare, Pyrite oxidation in alkaline solutions: nature of the product layer, Mineral processing, 72, 373-386, 2003.

[16] A. Gurses, K. Doymus, and S. Bayrakceken, Evaluation of response of brown coal to selective oil agglomeration by zeta potential measurements of the agglomerates, Fuel, 76, 1439-1444, 1997.

[17] D. Das, U. Dash, A. Nayk, and P.K. Misra, Surface Engineering of Low Rank Indian Coals by Starch - Based Additives for the Formulation of Concentrated Coal - Water Slurry, Energy Fuels, 24, 1260-1268, 2010.

[18] A. Ozkan, H. Ucbetiay, and S. Duzyol, Comparison of stages in oil agglomeration process of quartz with sodium oleate in the presence $\mathrm{Ca}$ and Mg ions, Journal of Colloid and Interface Science, 329, 81-88, 2009.

[19] A. Giirses, K. Doymug and S. Bayrakgeken, Evaluation of response of brown coal to selective oil agglomeration by zeta potential measurements of the agglomerates, Fuel, 76, 1439-1444, 1997. 